\title{
Baseline and dynamic expression of activating NK cell receptors in the control of chronic viral infections: the paradigm of HIV-1 and HCV
}

\author{
Francesco Marras ${ }^{1 \dagger}$, Federica Bozzano ${ }^{2,3 \dagger}$, Maria Libera Ascierto ${ }^{2,4}$ and Andrea De Maria ${ }^{2,5,6 *}$ \\ 1 Istituto Giannina Gaslini, Genova, Italy \\ ${ }^{2}$ Center of Excellence for Biomedical Research, University of Genova, Genova, Italy \\ ${ }^{3}$ Department of Experimental Medicine, University of Genova, Genova, Italy \\ ${ }^{4}$ Department of Oncology, Johns Hopkins University, Baltimore, MD, USA \\ ${ }^{5}$ Department of Health Sciences, University of Genova, Genova, Italy \\ ${ }^{6}$ Clinica Malattie Infettive, IRCCS A.O.U. S. Martino-IST, Istituto Nazionale Ricerca sul Cancro, Genova, Italy
}

\section{Edited by:}

Massimo Vitale, IRCCS A.O.U.S.

Martino-IST, Italy

\section{Reviewed by:}

Francisco Borrego, Cruces University Hospital, Spain

Vincent Vieillard, Institut National de la Santé et de la Recherche Scientifique, France

\section{*Correspondence:}

Andrea De Maria, University of

Genova, Largo R. Benzi 10, Genova 16132, Italy

e-mail:de-maria@unige.it

${ }^{\dagger}$ Francesco Marras and Federica Bozzano have contributed equally to this work.
Natural killer (NK) cell function is regulated by a balance between the triggering of activating and inhibitory receptors expressed on their surface. A relevant effort has been focused so far on the study of KIR carriage/expression setting the basis for NK cell education and self-tolerance. Focus on the evolution and regulation of activating NK receptors has lagged behind so far. Our understanding of activating receptor expression and regulation has recently improved by evidences derived from in vitro and in vivo studies. Virus infection - either acute or chronic - determines preferential expansion of NK cells with specific phenotype, activating receptors, and with recall-like functional activity. Studies on patients with viral infection (HIV and HCV) and specific diverging clinical courses confirm that inter-individual differences may exist in baseline expression of natural cytotoxicity receptors (NKp46 and NKp30). The findings that patients with divergent clinical courses have different kinetics of activating receptor density expression upon NK cell activation in vitro provide an additional, time-dependent, functional parameter. Kinetic changes in receptor expression thus represent an additional parameter to basal receptor density expression. Different expression and inducibilities of activating receptors on NK cells contribute to the high diversity of NK cell populations and may help our understanding of the inter-individual differences in innate responses that underlie divergent disease courses.

Keywords: natural cytotoxicity receptors, NKp46, NKp30, HIV, HCV, regulation

\section{INTRODUCTION}

Natural killer (NK) cells represent a cellular component of the innate immune system. They circulate in peripheral blood and peripheral tissues, and may be more abundantly recovered in secondary lymphoid organs and in some non-lymphoid organs (e.g., the liver). They are characterized by considerable cytotoxic activity, which is due to the constitutive expression of perforin and granzyme, which may be promptly released upon cell triggering $(1,2)$. In addition to this unique feature, which contributes to the high efficiency with which NK cells are suited to kill virally infected or tumor cells, their function also includes the production of cytokines, such as IFN- $\gamma$, tumor necrosis factor (TNF $\alpha$ ) and G-CSF, and the early release of chemokines (MIP-1a/b, RANTES) (3). NK cell function is finely regulated by the interplay of a wide array of activating and inhibitory receptors expressed on their surface (1). The accurate regulation of this signaling system guarantees that under baseline conditions their exceptional ability to rapidly kill is harnessed by inhibitory receptors mostly (but not exclusively, e.g., Siglec7 and IRP60) specific for "self" MHC class
I molecules (2), which turn NK cells "off" and normally prevent NK-mediated lysis of HLA class $\mathrm{I}^{+}$autologous cells.

Natural killer cell activating stimuli are manifold and act through triggering of different groups of receptors expressed on their surface (4). Activation of NK cells is determined by triggering the major activating receptors, which include NKp46, NKp30, NKp44 (i.e., natural cytotoxicity receptors, NCRs) NKG2D, and $\mathrm{F} c \gamma \mathrm{R}(\mathrm{CD} 16)$ as well as other receptors and co-receptors including, NKG2C (a lectin-type triggering receptor which dimerizes with CD94), 2B4 (CD244), NKp80, DNAM-1, and NTB-A (5). Stimuli delivered through other groups of receptors may also determine NK cell activation including toll-like receptors (TLRs) as TLR2, TLR3, TLR7/8, TLR9, and interleukin receptors (IL-2, IL-12, IL-15, IL-18) and combinations thereof (e.g., IL-2 + IL-15, IL-2 + IL-12, and IL-12 + IL-18) (5-7).

The NK cell receptors repertoire is germ line-encoded and does not undergo somatic recombination. This provides the basis for inclusion of NK cells among innate host defenses as an effective and apparently basic unsophisticated innate defense system which 
does not need specific recognition of foreign antigens (e.g., from pathogens or tumors).

\section{INVOLVEMENT OF NK CELLS IN THE TUNING AND CONTROL OF IMMUNE RESPONSES}

The original view of NK cells as a purely "primitive," muscular, short-lived, rapid responder cell type has undergone considerable revision and has been considerably updated over recent years. NK cells are presently known to represent long-lived innate cells, whose functional spectrum extends beyond classical search-and-destroy patrolling activity and/or early recruitment of immune responses. NK cell function indeed also includes regulation of other innate and adaptive functions through their direct or indirect reciprocal interaction (crosstalk) with macrophages, polymorphonuclear cells $(6,7)$, fibroblasts (8), DC (9-11), and T cells.

Natural killer cells interact with and respond to either pathogen-infected or tumor-associated macrophages, and their response is modulated by macrophage functional polarization. The functional interaction of $\mathrm{NK}$ cells with proinflammatory (M1) or anti-inflammatory (M2) macrophages relies on DNAM-1,2B4, and NKp46 receptor signaling, in addition to membrane-bound macrophage-derived IL-18 (12-14). Considering macrophages infected with specific pathogens, different sets of activating receptor-ligand interactions drive NK cell activation in a more pathogen-dependent pattern $(6,11,15)$. A decreased NK cell response has been described during their interaction with M2 cells compared to M1 macrophages, or in the tumor environment where NK cell activating receptors are down-regulated (13, 14). In view of the reported recognition of mycobacteria-infected macrophages by NK cells via NKp46 (15), decreased signaling via NKp46 in patients with overt secondary pulmonary TB (16) could represent for example a possible mechanism participating in the so far poorly understood mechanism of exit from latent TB (17).

The reciprocal interaction of NK cells and DC is often referred to as "crosstalk" and involves multiple receptors and cytokines. NK cells and DC show anatomical and functional co-localization in T cell areas of lymphnodes (18) and in inflamed tissues (19). Human DC activate NK cells, via direct interaction and involvement of NKp30 $(10,20)$ and DNAM-1 (9). NK cells determine lysis of immature HLA class $\mathrm{I}^{-/ \text {low }}$ DC, while mature DC are protected from NK-mediated lysis by high density expression of HLA class I molecules that interact with inhibitory receptors (e.g., KIR) expressed on activated NK cells (11). In turn, NK cells induce DC maturation via TNF $\alpha$ and IFN $\gamma$ production (10). This DCNK cell interaction provides a mechanism to edit DC responses and their repertoire by selecting optimally mature DCs (21) and inducing DC to express high amounts of membrane-associated IL-15 (22) with impact on downstream adaptive responses (23). These observations are further supported by the demonstration, in vitro with bacterial infection (24) and in vivo during HIV infection that the presence of reduced NCR expression (25) and NK cell subset alterations (26) leads to reduced killing of immature DC (20).

Involvement of NK cells in the shaping of adaptive responses extends beyond their crosstalk with DC. In fact, NK cells also directly interact with $\mathrm{T}$ cells, favoring antigen-specific $\mathrm{CD} 8^{+} \mathrm{T}$ cell responses $(22,23,27)$. The reciprocity of this circuit has been elegantly shown in the macaque model where Ag-specific $\mathrm{CD} 4^{+}$ T-central memory lymphocytes support NK cell activation and function in SIV-controller donors (28).

Therefore, a relevant part of the tuning activity of NK cells on the function and control of other cells is based on direct cell-to-cell interactions and involves activating NK cell receptors. Consequently, different activating NK cell receptor molecule densities may have an impact on their crosstalk with other cells of the immune system. The purpose of this review is to provide a reading frame to differences in static and dynamic NCR expression in subjects displaying clinical divergence upon infection with different viruses.

\section{INNATE OR NOT INNATE, THIS IS THE QUESTION}

Until recently, the prevailing expert view attributed to NK cells a limited degree of variability in response to pathogens, and basically assumed stereotyped responses. This concept practically ruled out the possibility of ranges of variability of NK cell responses either against different pathogens within the same subject or to the same pathogen within different patients. This view has been steadily upgraded in recent years. It has been shown for example in mice that infection with viruses and other pathogens determines the expansion of specific NK cell subsets (29-31) which maintain for prolonged periods of time the ability to produce increased amounts of TNF $\alpha$ and IFN $\gamma$. This observation is reminiscent of memory $\mathrm{T}$ cell function thus suggesting a possible memory-like feature of NK cells. Subsequent observations in human beings showed that also human CMV infection leads to expansion of a subset of $\mathrm{NKG}_{2} \mathrm{C}^{+} \mathrm{NK}$ cells $(32,33)$ with memory-like properties. Increased proportions of $\mathrm{NKG}_{2} \mathrm{C}^{+} \mathrm{NK}$ cells persist (34) after acute infection into latency, and may be observed also after bone marrow transplantation $(34,35)$. Additional evidences of transient NK cell expansions in human beings are provided by infection with chikungunya and hantavirus (36, 37), and may persist up to 60-90 days. Also in these instances the expanded cells are exclusively $\mathrm{NKG}_{2} \mathrm{C}^{+}$, and their triggering results in increased and rapid reactivity with production of IFN $\gamma$ upon re-challenge. These observations are clearly different from $\mathrm{T}$ cell memory, which is conventionally defined by (life)longlasting antigen-specific recall ability, increased memory $\mathrm{T}$ cell receptor (TCR) density, antigen-specific TCRs, and specific markers identifying memory cells (CD45RO vs. CD45RA) $(31,38)$. In mice, $\mathrm{LY}_{4} 9 \mathrm{H}^{+}-\mathrm{MCMVm} 157$ antigen-specificity and increased protection to Mouse CMV (MCMV) challenge support a resemblance with memory $\mathrm{T}$ cell protection $(31,39)$. In human beings, on the other hand, the expansions are more time-limited with the possible exception of HCMV infection and latency. These human NK cell subset expansions are stereotyped and monomorphic since only $\mathrm{NKG}_{2} \mathrm{C}^{+}$cell expansions are reported, irrespective of the invading pathogen (either HCMV, or hantavirus or chikungunya).

Altogether, the description of pathogen-induced recall NK cell reactivity, even if not fitting with a long-lasting heterogeneous $\mathrm{T}$ cell memory $(40,41)$, has the merit of further expanding our understanding of NK cell function advancing our view beyond the original "first-line of defense" towards a wider horizon of multifaceted NK cell function. 
An interesting contribution to the notion of a polymorphism in NK cell responses has been recently provided by mass cytometry study of NK cell receptor carriage (42) showing that up to 30,000 different phenotypic NK cell populations may be harbored in one individual. In addition, environmental factors appear to heavily influence activating receptor carriage, while inhibitory receptor diversity seems to be largely genetically determined (42). In line with this observation, NK cell responses induced by virus(es) are accompanied, not only by expansion of a subset of peripheral NK cells which may be $\mathrm{NKG} 2 \mathrm{C}^{+}(33)$, but also by changes in triggering receptor expression (e.g., NCRs) (34).

\section{NCR EXPRESSION AND HCV INFECTION}

Natural killer cell triggering receptors recognize specific ligands induced by either cell transformation or infection [e.g., B7-H6 (41, 43)]. Although cellular ligands for NCRs are still not yet well characterized (e.g., NKp46-L, NKp44-L, and other NKp30-ligands), a range of pathogens including influenza virus, parainfluenza virus, West Nile virus (WNV), dengue virus, and mycobacteria have been shown to interact with NCRs, either directly or after their infection of target cells (44). Accordingly, NK cell first-line defenses against pathogens and regulation of immune responses may be more intertwined than expected at a first look. Indeed, the same receptors that are involved in recognition of infected cells may be also involved in direct pathogen detection and in crosstalk with other cells of the immune system (e.g., monocytes and dendritic cells). Hence, individual differences in baseline NCR expression may underlie and affect divergent host responses to the pathogen.

Natural killer cell triggering is proportional to both the actual number/density of a given triggering receptor expressed on NK cells and to the density of the respective ligand(s) expressed on target cells. At any given level of KIR/HLA interaction and of NK-ligand expression, changes in activating receptor expression density determines proportional changes in NK cell cytotoxic activity $(45,46)$.

Accordingly, wide inter-individual variations in triggering receptor expression could contribute, at least in part, to the different clinical courses (e.g., from mild disease to life-threatening clinical course) that are observed in patients infected by the same pathogen. When for example considering NKp46 and influenza hemagglutinin (HA), NKp46 (and NKG2D) is necessary for the activation of the human response to influenza infection $(47,48)$. In mice, induced deletion of the human NKp46 homolog (NCR1) determines lethal influenza infection (49). In addition, NK cell function is impaired in aging mice infected with influenza virus, with reduced production of IFN- $\gamma$ also upon stimulation with anti-NKp46 mAbs, in line with the suggestion of reduced receptor expression $(49,50)$.

The possibility that different levels of NCR expression may correlate to different clinical courses emerges also from studies in patients with HCV infection. A relevant association exists between outcome of acute HCV infection and germline carriage of KIR genes and HLA C supertypes $(51,52)$. Also activating NK cell receptor expression has been shown to associate with different disease courses during HCV infection. In the acute phase of HCV infection, an increase in CD56 $6^{\text {bright }} \mathrm{NK}$ cells is observed, and is accompanied by a reciprocal reduction in CD56 ${ }^{\text {dim }}$ cells (53). In patients who spontaneously clear the virus (HCV), the increase in CD56 ${ }^{\text {bright }}$ NK cells is transient, with subsequent decline within 1-3 months. This change is however permanent in those who fail to clear HCV and proceed to chronic infection with virus replication (53). Interestingly, NKp30 expression is increased in NK cells from multiply HCV exposed-uninfected intravenous drug users. In these patients, enhanced IL-2-induced cytolytic activity against the NK-sensitive cell line K562 has been also reported (54). The same mechanism of NKp30-associated protection applies to the control of in vitro hepatocyte infection (54). In a recent and different setting, increased NKp46, NKp44, and NKG2A expression was detected in NK cells from HCV exposed healthcare workers (HCW), who did not develop disease (55). Interestingly, in this series, HCV-specific T cell responses to non-structural gene products were detected in the absence of $\mathrm{B}$ cell responses and of HCV-specific antibody production. This observation is reminiscent of a phenomenon occurring in HIV-uninfected children born to HIV-seropositive mothers. These children lose maternal antibodies are uninfected and seronegative, but show HIV-specific cytotoxic activity by $\mathrm{CD}^{+} \mathrm{T}$ cells $(56,57)$. An analogy is evident in results obtained 20-years apart in different models of human infection and raises the possibility that inducibility of NCRs on NK cells in some patients may be associated with discordant $\mathrm{T}$ and $\mathrm{B}$ cell responses and with protection from infection.

Differences in NCR expression are detected also when exposed patients become acutely infected and display HCV viremia. In this case, lower frequencies of NKp46- and NKp30-expressing NK cells are observed compared to healthy donors, and this phenotype correlates with HCV clearance (58). Thus, NCR (NKp46 and NKp30) expression on peripheral NK cells is different when acutely infected patients (low NCRs) are compared to exposed-uninfected patients (high NCRs). The observed difference may be for example due to inherent, preexisting baseline differences that become evident following patient selection in different series. Alternatively, in patients who resolve acute infection, the lower expression of NKp46- and NKp30 molecules on NK cells could be due to increased margination of NK cells to the site of active HCV replication (i.e., liver) (59). A further possible explanation for these differences could be represented by different inductions of NCR expression in different patient groups upon challenge with the virus (HCV). In such a scenario, early responders would rapidly upregulate NCR expression, avoid establishment of infection, and evolve to the clinical state of exposed-uninfected subjects.

During chronic HCV infection, imbalances in peripheral NK cells were originally described, with a deficient ability to activate DCs due to the interaction of NKG2A with HLA-E expressed on hepatocytes (60). This interaction is associated to IL-10 production $(60,61)$ and to reduced ability of IFN $\gamma$ production upon IL-12 stimulation or with other stimuli (62). With regard to NCR expression, either increases or decreases in NCR expression are observed $(61,63)$ and are related to their ability to respond to IFN$\alpha$-containing treatment regimens. Indeed, patients who clear the infection upon dual treatment with pegylated-IFN- $\alpha+$ ribavirin (PegIFN $\alpha$-ribavirin) have lower baseline (pre-treatment) expression of NKp30 and of CD85j, compared to those who subsequently fail the treatment (null responders, partial responders) (64). The decreased expression of NKp30 in these patients is not reflecting 
a defect in NK cell function, but rather an individual difference in the regulation of receptor expression. This is confirmed by the successful induction in vitro of NKp30 expression on purified NK cells cultured in the presence of IFN- $\alpha$, with correspondingly increased receptor-mediated function. These observations are in line with evidences deriving from the study of intrahepatic interferon-stimulated gene (ISG) expression $(65,66)$. In the liver, ISG is already upregulated before treatment in patients who will not respond to IFN- $\alpha$ and ribavirin dual treatment. Patients who will clear virus upon treatment, on the contrary, have baseline lower ISG expression which may be induced during treatment (66). Thus, inherent individual regulation of crucial gene expression is present during chronic HCV infection and extends from ISG in hepatocytes to NCRs.

Therefore, differences in baseline NCR expression and in NK cell phenotype can be accurately detected (42) and are associated with diverging clinical courses in subjects exposed to HCV. Lower NCR expression, albeit inducible, represents an advantage and appears to be inherently regulated in a subset of chronically infected patients. In this context, the increased NCR expression observed on NK cells in exposed-uninfected patients may be the result of repeated HCV challenge in patients with lower baseline NCR expression.

\section{NCR EXPRESSION AND DIVERGING CLINICAL COURSES IN HIV INFECTION}

During HIV infection, the virus targets NK cell-mediated responses with similar or possibly higher intensity compared to other arms of innate or adaptive immunity. NK cells are part of the early response that controls acute viremia during primary HIV infection. Similar to HCV exposed-uninfected patients $(54,55)$, increased NK cell activity has been detected also in HIV exposeduninfected patients (67). Activating receptor expression was not addressed in this work, and materials for monitoring (anti-NCR mAbs) were not yet available at the time. Although the mechanisms leading to increased NK cell function in those HIV exposeduninfected remain still not defined, increases in the expression of triggering receptors on NK cells could have been possible, similar to what has been observed after exposure to $\operatorname{HCV}(54,55)$. If so, this would fit in a broad concept of an advantage against infection in subjects whose NK cells achieve rapid dynamic increases in NCR expression after virus challenge.

Once HIV viremia is established, NK cell derangement can be detected in infected patients soon thereafter (68-70) and includes imbalances in activating and inhibitory receptor expression, altered circulation of NK cell subsets, and impairment of NK cell function $(25,26,71,72)$. Viremic HIV-patients have dramatic decreases in activating receptor expression (NKp46 and NKp30) on NK cells in vivo (25), up to one-third of circulating NK cells display activation markers (HLA-DR and CD69) (72) and an apparently poorly functional subset of $\mathrm{CD} 56^{-} \mathrm{CD} 16^{+}$appears, which displays expression of low levels of NCRs $(26,72)$. The impairment of NK cell function has a relevant impact on DC editing. In addition to the reduced activating receptor expression on NK cells and appearance of poorly functional $\mathrm{CD} 56^{-} \mathrm{CD} 16^{+}$ NK cells in peripheral blood, HIV infection reduces the expression on $\mathrm{CD} 4^{+} \mathrm{T}$ and other target cells of ligands of activating NK cell receptors which are important in triggering NK cell cytotoxicity and cytokine production (e.g., PVR, NKp46-L, and NKp30-L) (73-76). Thus, while HIV adopts multiple strategies to evade NK cell surveillance, conserved (or restoration of) activating receptor function may represent a fundamental barrier to virus spread.

From a clinical standpoint, during the first years of the epidemic, it became soon clear that consistent clinical variability could be observed among patients even in the absence of successful treatment. A benign disease course in otherwise untreated patients was identified through the observation of HIV-infected patients with long-term non-progressing disease (i.e., high $\mathrm{CD}^{+} \mathrm{T}$ cells $>450 / \mu l$ and low level viremia, LTNP) and of patients with high $\mathrm{CD}^{+}$T-lymphocytes and undetectable viremia (elite controller, EC) $(77,78)$. In addition, upon progressive disease with decreasing $\mathrm{CD} 4{ }^{+}$cell counts, diverging courses are observed. At any given $\mathrm{CD}^{-}$count, opportunistic infections or cancers may appear in some - but not all - patients (79-81) and AIDS-defining disease including Kaposi Sarcoma, non-Hodgkin Lymphoma, or Tuberculosis may occur before $\mathrm{CD}^{+}$counts fall below 200-350/ $\mu \mathrm{l}$ (82-85). On the other hand, in the pre-highly active antiretroviral treatment (HAART) era, some untreated patients could reach very low $\mathrm{CD} 4{ }^{+} \mathrm{T}$ cell counts without progressing to AIDS and showed surprisingly preserved NK cell numbers and function (86). Following HAART, NK cells fail to fully recover IFN- $\gamma$ production and phenotype $(87,88)$ and surprisingly maintain high levels of activation, as defined by HLA-DR expression $(46,89)$. This extensive list of examples shows the profound impact of personal clinical divergence in everyday HIV clinical practice.

Divergent clinical courses during HIV infection cannot be fully accounted for by $\mathrm{CD}^{+}$cell numbers alone. Data from NK cell function and receptor expression may be used in this context to help understand existing differences. When antiretroviral treatment is interrupted in chronically infected patients, viral replication invariably resumes even after thorough and extensive treatment (90). Trials of $\mathrm{CD}^{+}{ }^{+}$-guided treatment interruptions (CD4GTI) in patients with high $\mathrm{CD}^{+} \mathrm{T}$ cell showed that the rate of $\mathrm{CD} 4^{+}$-cell loss after discontinuation of antiretroviral treatment is dishomogeneous with ample divergence and inter-individual differences (91, 92). Factors associated with different rates of $\mathrm{CD}^{+} \mathrm{T}$ cell loss upon CD4GTI include not only proviral DNA changes (93), increased proportion of $\mathrm{CD}^{+} \mathrm{CD} 127^{+}$cells $(94$, 95), but also a different baseline NK cell expression and function (96). At baseline (i.e., before treatment interruption), patients with long treatment interruptions (i.e., without the need of resuming HAART) due to persistently high $\mathrm{CD}^{+}$cell counts had lower proportions of $\mathrm{CD} 56^{\text {bright }} \mathrm{CD} 16^{ \pm} \mathrm{NK}$ cells, and also expressed lower levels of NKp30 and NKp46 activating receptors on NK cells (96). Interestingly, this observation is in agreement with the findings from chronically $\mathrm{HCV}$-infected patients, where those who will clear the virus after PegIFN $\alpha$-ribavirin treatment have low and inducible - NCR (NKp30) expression on their NK cells at baseline (64).

In addition, inherent differences in NK cell receptor expression are observed also in $\mathrm{HIV}$-patients with low $\mathrm{CD}^{+}$cell counts $(<220 / \mu \mathrm{l})$ but divergent clinical course. Those who have AIDS-defining opportunistic infections (i.e., PCP and neurotoxoplasmosis) have lower NKp46 expression and low 
DNAM-1/NKG2D/NCR:ligand ratios compared to patients who reach similarly low $\mathrm{CD}^{+}{ }^{+}$cell counts but do not develop AIDS (46). These results therefore indicate that similar to HCV patients, differences in NK cell regulation underlie divergent clinical courses also in HIV-patients, irrespective of their CD4 ${ }^{+} \mathrm{T}$ cell count, of HAART or virus replication. Importantly, this view is not limited to chronic infections. Support to the general view of inherent specific NK cell signatures underlying divergent disease course is provided also from analyses in cancer patients with recurrent disease, either gastrointestinal stromal tumor (GIST) (97) or breast cancer (98).

\section{INDUCIBLE NCR EXPRESSION AND CLINICAL DIVERGENT DISEASE COURSES}

Although analysis of NCR expression on peripheral NK cells may reflect baseline regulations in NK cell subsets, it represents only a "frozen" view and does not provide insights on their inducibility or "dynamic" regulation. In this regard, in vitro study of NCR expression in purified NK cells recently revealed that different induction kinetics over time may be detected in HIV-patients (99). Indeed, when patients with non-progressive disease course (EC and LTNP) were compared to HAART-treated aviremic patients, relevant differences were detected. In EC/LTNP patients, purified NK cells display increased NKp46 expression 2 days after in vitro activation with IL-2, with subsequent return to baseline expression 4 days thereafter. Also NKp30 expression is induced in EC/LTNP upon in vitro activation with progressive increased densities until 4 days after activation. On the contrary, HAARTtreated progressor patients with undetectable HIV-RNA do not show any induction of NKp46 or NKp30 (99). The conserved induction of NCRs in non-progressor patients provides the basis for an intact NK cell function, conserved crosstalk with DCs and downstream specific CD8 ${ }^{+}$CTL responses $(20,100,101)$. Interestingly, also in HCV-infected patients inducibility of $\mathrm{NKp} 30$ is associated with a different (improved) disease course compared to patients lacking this regulation (64). An additional observation of considerable interest in this context was the lack of inducibility of NKp44 in EC/LTNP patients compared to progressor patients (99). This apparent "fault" with failure to rapidly upregulate NKp44 molecule expression upon activation, might actually be highly protective once HIV infection has established. Indeed, $\mathrm{HIV}_{\mathrm{gp} 41}$ S3 peptide shedding in infected patients (102) induces expression of NKp44-ligands in uninfected CD4 ${ }^{+} \mathrm{T}$ cells. The apparent "faulty" induction of NKp44 thus would avoid innocent bystander killing of $\mathrm{CD}^{+}{ }^{+} \mathrm{NKp} 44-\mathrm{L}^{+}$cells by activated NK cells in vivo. Support to this hypothesis is directly provided by the demonstration that $\mathrm{HIV}_{\mathrm{gp} 41}$ vaccination prevents from shedding of the S3 peptide and from NKp44-L expression thus protecting CD4 ${ }^{+}$ $\mathrm{T}_{\mathrm{CM}}$-lymphocytes in SHIV-infected non-human primates (103).

A limitation to interpretation of NCR expression/induction is represented by the lack of molecular and genetic proof so far in the regulation of NCR responses and inducibility, with only
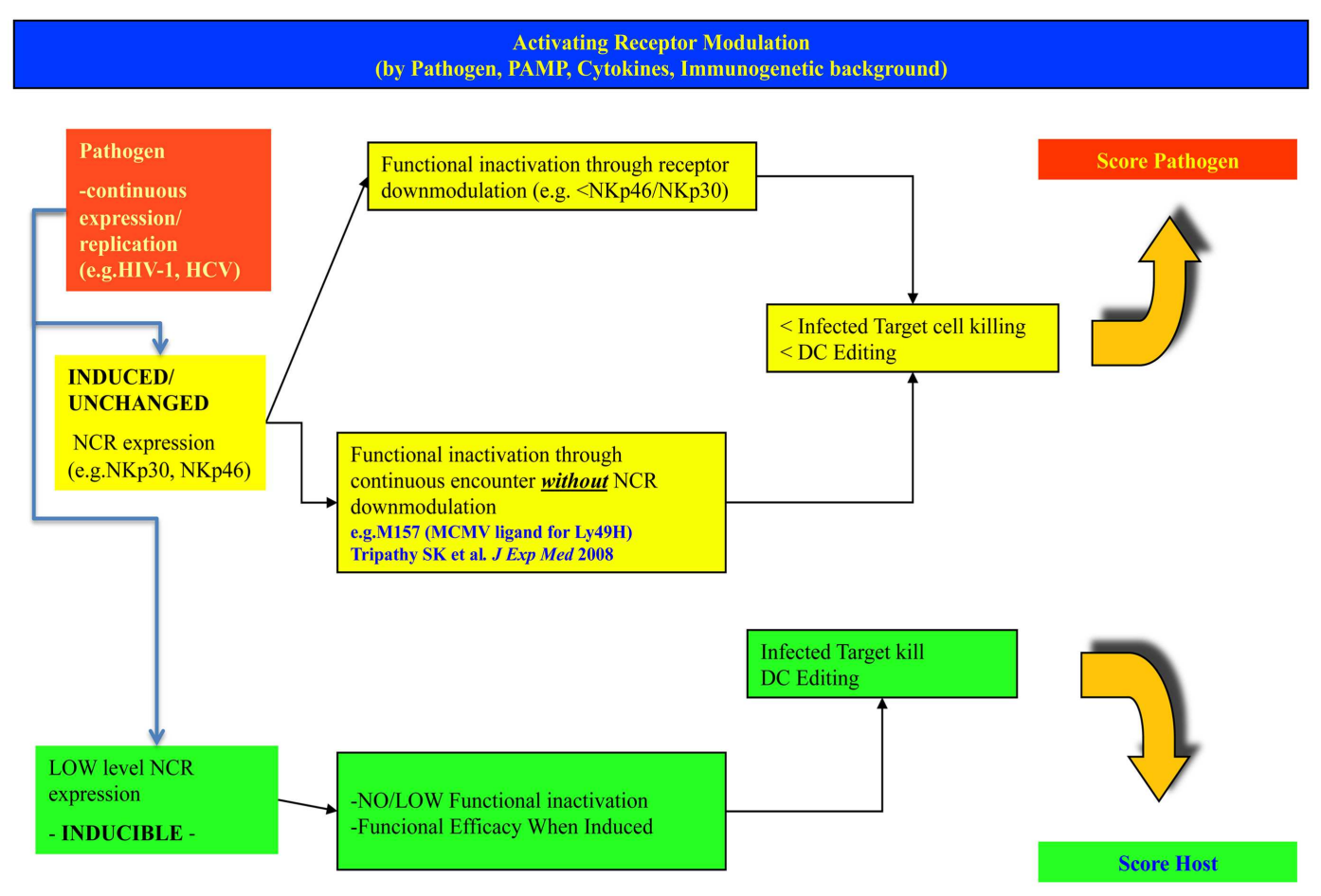

FIGURE 1 | Different levels and modulation of natural cytotoxicity receptors on NK cells may lead to different outcomes in the fight against invading intracellular pathogens. The figure indicates possible alternate patterns of NK cell NCR expression/induction upon infection with a pathogen. In the upper row, the case for high basal expression is shown, leading to receptor inactivation and progressive infection. In the lower row, the case of a low/inducible NCR expression is shown, with inducibility upon strong challenge with successful control of the pathogen. The hypothesis considers a spectrum of intermediate conditions (not shown here). 
limited information being available (104). Also, there is poor understanding of the mechanism(s) underlying "protection" from adverse disease in the presence of low-inducible activating receptor expression. It has been suggested that low-inducible NCR expression may provide advantage in the case of overwhelming stimulation of NK cells due to a relative preservation from their excessive activation with detrimental activation of other innate and adaptive immune mechanism(s) (44). In this regard, it has been shown that homo-oligomerization of NKp30 in the plasma membrane of NK cells is favored by IL-2-dependent up-regulation of NKp30 expression and improves recognition and lysis of target cells by NK cells (105). Interestingly, independent studies showed that viruses may address NKp30 receptors inactivating their function, as shown for NKp30 signaling by vaccinia virus HA (106). Thus, low expression of NKp30 with maintained inducibility, as in the case of HCV and HIV $(64,96,99)$, could represent an advantageous inherent individual trait. Subjects carrying this characteristic would evade NK cell-targeting by virus(es) due to lower exposure of a given NCR (e.g., NKp30) to hyperactivation and inactivation (107). At the same time, they would still be able to upregulate molecule density upon activation (e.g., IL-2 and IFN $\alpha$ ) thus reaching critical receptor homo-oligomerization with binding to its ligand (e.g., infected cells and DCs).

Evidences supporting memory-like NK cell responses and those showing inducibility of NCR receptor expression on NK cells are derived from clearly distinct settings and should be considered unrelated unless differently proven. Indeed, changes in cytokine production and in activating receptor expression have been reported during memory-like NK cell responses following CMV, hantavirus, or chikungunya virus infection $(34,36$, 37), while NKp30 inducibility has been observed in some HCV or HIV infected patients $(16,96,99)$. In addition, memory-like $\mathrm{NK}$ cell responses have been so far attributed only to $\mathrm{NKG}_{2} \mathrm{C}^{+}$ NK cells, while NCR inducible NK cell responses are largely NKG2C unrelated, and show a considerably shorter kinetic (2-4 vs. 30-60 days).

The concept of host antiviral NK cell-associated defenses may however be expanded to encompass both rapid inducibility of NK cell responses after virus infection and memory-like NK cell responses within the frame of NK cell diversity modulated by environmental factors (42). Diverging NCR inducibility, similar to memory-like NKG2C expansion both contribute to host protection and may represent different perspectives of a multifaceted ability of NK cells to adapt to tackle different invading pathogens.

\section{CONCLUSION}

Manifold inter-individual differences in the regulation of innate defenses have been described until very recently. The immunogenotype of several components of innate immunity strongly influences the risk to contract infections and also the outcome of their treatment. Genome-wide association studies showed that polymorphisms of innate components are associated to individual variable response to treatment and to disease progression. Nucleotide polymorphisms of TLRs [TLR-4 (108, 109), TLR-1 and 6 (110) ] and of pentraxin-3 (111) are associated to increased risk of invasive aspergillosis or mycosis in bone marrow transplant

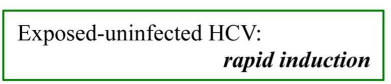

Cleared acute HCV infection: induction then decrease Chronic HCV infection with SVR to
peg-IFNa+ribavirin:
Low, inducible upon $T \boldsymbol{x}$ HIV non-progressors (LTNP, EC) Low, inducible in vitro

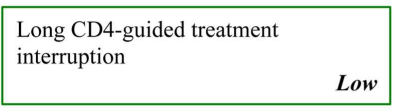

Acute $\mathrm{HCV}$ infection progressing to chronicity: Persistent upregulation

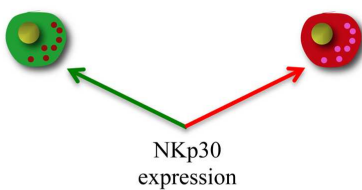
peg-IFNa+ribavirin:

High expression, persistent

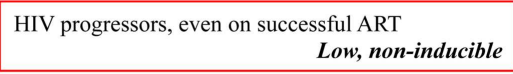

Short CD4-guided treatment interruption

High

According to: Amadei B et al. Gastronterology 2010; Golden-Mason L et al. Hepatology 2010; Werner JM et al. Hepatology 2013; Alter G et al. J Hepatol 2011; De Maria et al. Eur J Immunol 2007; Bozzano F et al. Eur J Immunol 2011; Bozzano F et al. Hum Immunol 2011; De Maria et al. Eur J Immunol 2003, Marras F. et al. Proc Natl Acad Sci USA 2013.

FIGURE 2 | Organization of evidences supporting clinical divergence in HIV-1 or HCV-infected patients according to NKp30 expression/regulation on peripheral NK cells. The left column lists evidences showing favourable disease course in the presence of receptor inducibility. The left column lists evidences for unfavourable disease course in the presence of high basal expression without inducibility or no inducibility regardless of expression. 
patients $(110,111)$. Similarly, TLR3 polymorphisms have been associated to pneumonia development in children with influenza virus infection (112). In addition, IL-28B single nucleotide polymorphisms are associated to prognosis of treatment in $\mathrm{HCV}$ infection using IFN- $\alpha$-containing regimens (113-116).

The presently discussed modulation of NCR expression (NKp30, NKp46, and NKp44) has been described also in chimpanzees (117), and thus appears to represent an innate mechanism of protection against chronic infections that is conserved in evolution and that provides inherent individual diversity in chronically infected (HIV and HCV) patients where it contributes to explain clinical divergence (Figures 1 and 2).

\section{ACKNOWLEDGMENTS}

The present work has been partially supported by grants awarded by Istituto Superiore di Sanità (ISS): Programma Nazionale di Ricerca sull' AIDS, Accordi di Collaborazione Scientifica no. 40G.41 and 45G.11, no. 40D61 and 40H69; Ministero della Salute RF-2010-2316197.

\section{REFERENCES}

1. Biassoni R, Cantoni C, Pende D, Sivori S, Parolini S, Vitale M, et al. Human natural killer cell receptors and co-receptors. Immunol Rev (2001) 181:203-14. doi:10.1034/j.1600-065X.2001.1810117.x

2. Moretta L, Locatelli F, Pende D, Sivori S, Falco M, Bottino C, et al. Human NK receptors: from the molecules to the therapy of high risk leukemias. FEBS Lett (2011) 585:1563-7. doi:10.1016/j.febslet.2011.04.061

3. Fauriat C, Long EO, Ljunggren H-G, Bryceson YT. Regulation of human NK cell cytokine and chemokine production by target cell recognition. Blood (2010) 115:2167-76. doi:10.1182/blood-2009-08-238469

4. Lee S-H, Miyagi T, Biron CA. Keeping NK cells in highly regulated antiviral warfare. Trends Immunol (2007) 28:252-9. doi:10.1016/j.it.2007.04.001

5. Moretta A, Bottino C, Vitale M, Pende D, Cantoni C, Mingari MC, et al. Activating receptors and coreceptors involved in human natural killer cell-mediated cytolysis. Annu Rev Immunol (2001) 19:197-223.

6. Costantini C, Micheletti A, Calzetti F, Perbellini O, Pizzolo G, Cassatella MA. Neutrophil activation and survival are modulated by interaction with NK cells. Int Immunol (2010) 22:827-38. doi:10.1093/intimm/dxq434

7. Mantovani A, Cassatella MA, Costantini C, Jaillon S. Neutrophils in the activation and regulation of innate and adaptive immunity. Nat Rev Immunol (2011) 11:519-31. doi:10.1038/nri3024

8. Balsamo M, Scordamaglia F, Pietra G, Manzini C, Cantoni C, Boitano M, et al. Melanoma-associated fibroblasts modulate NK cell phenotype and antitumor cytotoxicity. Proc Natl Acad Sci U S A (2009) 106:20847-52. doi:10.1073/pnas. 0906481106

9. Pende D, Castriconi R, Romagnani P, Spaggiari GM, Marcenaro S, Dondero A, et al. Expression of the DNAM-1 ligands, Nectin-2 (CD112) and poliovirus receptor (CD155), on dendritic cells: relevance for natural killer-dendritic cell interaction. Blood (2006) 107:2030-6. doi:10.1182/blood-2005-07-2696

10. Vitale M, Della Chiesa M, Carlomagno S, Pende D, Arico M, Moretta L, et al. DC maturation is mediated by TNFalpha and IFNgamma released upon engagement of the NKp30 triggering receptor. Blood (2005) 106:566-71. doi:10.1182/blood-2004-10-4035

11. Ferlazzo G, Tsang ML, Moretta L, Melioli G, Steinman RM, Munz C. Human dendritic cells activate resting natural killer (NK) cells and are recognized via the NKp30 receptor by activated NK cells. J Exp Med (2002) 195:343-51. doi:10.1084/jem.20011149

12. Michel T, Hentges F, Zimmer J. Consequences of the crosstalk between monocytes/macrophages and natural killer cells. Front Immunol (2013) 3:403. doi:10.3389/fimmu.2012.00403

13. Bellora F, Castriconi R, Dondero A, Reggiardo G, Moretta L, Mantovani A, et al. The interaction of human natural killer cells with either unpolarized or polarized macrophages results in different functional outcomes. Proc Natl Acad Sci U S A (2010) 107:21659-64. doi:10.1073/pnas.1007654108
14. Bellora F, Castriconi R, Dondero A, Pessino A, Nencioni A, Liggieri G, et al. TLR activation of tumor-associated macrophages from ovarian cancer patients triggers cytolytic activity of NK cells. Eur J Immunol (2014) 44(6):1814-22. doi:10.1002/eji.201344130

15. Vankayalapati R, Wizel B, Weis SE, Safi H, Lakey DL, Mandelboim O, et al. The NKp46 receptor contributes to NK cell lysis of mononuclear phagocytes infected with an intracellular bacterium. J Immunol (2002) 168:3451-7. doi:10.4049/jimmunol.168.7.3451

16. Bozzano F, Costa P, Passalacqua G, Dodi F, Ravera S, Pagano G, et al. Functionally relevant decreases in activatory receptor expression on NK cells are associated with pulmonary tuberculosis in vivo and persist after successful treatment. Int Immunol (2009) 21:779-91. doi:10.1093/intimm/dxp046

17. Bozzano F, Marras F, De Maria A. Immunology of tuberculosis. Mediterr J Hematol Infect Dis (2014) 6(1):e2014027. doi:10.4084/mjhid.2014.027

18. Ferlazzo G, Pack M, Thomas D, Paludan C, Schmid D, Strowig T, et al. Distinct roles of IL-12 and IL-15 in human natural killer cell activation by dendritic cells from secondary lymphoid organs. Proc Natl Acad Sci U S A (2004) 101:16606-11. doi:10.1073/pnas.0407522101

19. Parolini S, Santoro A, Marcenaro E, Luini W, Massardi L, Facchetti F, et al. The role of chemerin in the colocalization of NK and dendritic cell subsets into inflamed tissues. Blood (2007) 109:3625-32. doi:10.1182/blood-2006-08038844

20. Mavilio D, Lombardo G, Kinter A, Fogli M, La Sala A, Ortolano S, et al. Characterization of the defective interaction between a subset of natural killer cells and dendritic cells in HIV-1 infection. J Exp Med (2006) 203:2339-50. doi:10.1084/jem.20060894

21. Moretta A. Natural killer cells and dendritic cells: rendezvous in abused tissues. Nat Rev Immunol (2002) 2:957-65. doi:10.1038/nri956

22. Morandi B, Mortara L, Carrega P, Cantoni C, Costa G, Accolla RS, et al. NK cells provide helper signal for CD8 $+\mathrm{T}$ cells by inducing the expression of membrane-bound IL-15 on DCs. Int Immunol (2009) 21:599-606. doi:10.1093/intimm/dxp029

23. Krebs P, Barnes MJ, Lampe K, Whitley K, Bahjat KS, Beutler B, et al. NK cellmediated killing of target cells triggers robust antigen-specific T cell-mediated and humoral responses. Blood (2009) 113:6593-602. doi:10.1182/blood-200901-201467

24. Ferlazzo G, Morandi B, D’Agostino A, Meazza R, Melioli G, Moretta A, et al. The interaction between NK cells and dendritic cells in bacterial infections results in rapid induction of NK cell activation and in the lysis of uninfected dendritic cells. Eur J Immunol (2003) 33:306-13. doi:10.1002/immu.200310004

25. De Maria A, Fogli M, Costa P, Murdaca G, Puppo F, Mavilio D, et al. The impaired NK cell cytolytic function in viremic HIV-1 infection is associated with a reduced surface expression of natural cytotoxicity receptors (NKp46, NKp30 and NKp44). Eur J Immunol (2003) 33:2410-8. doi:10.1002/ eji.200324141

26. Mavilio D, Lombardo G, Benjamin J, Kim D, Follman D, Marcenaro E, et al. Characterization of CD56-/CD16+ natural killer (NK) cells: a highly dysfunctional NK subset expanded in HIV-infected viremic individuals. Proc Natl Acad Sci U S A (2005) 102:2886-91. doi:10.1073/pnas.0409872102

27. Vankayalapati R, Klucar P, Wizel B, Weis SE, Samten B, Safi H, et al. NK cells regulate $\mathrm{CD} 8+\mathrm{T}$ cell effector function in response to an intracellular pathogen. J Immunol (2004) 172:130-7. doi:10.4049/jimmunol.172.1.130

28. Vargas-Inchaustegui DA, Xiao P, Tuero I, Patterson LJ, Robert-Guroff M. NK and CD4+ T cell cooperative immune responses correlate with control of disease in a macaque simian immunodeficiency virus infection model. J Immunol (2012) 189:1878-85. doi:10.4049/jimmunol.1201026

29. Paust S, Gill HS, Wang B-Z, Flynn MP, Moseman EA, Senman B, et al. Critical role for the chemokine receptor CXCR6 in NK cell-mediated antigenspecific memory of haptens and viruses. Nat Immunol (2010) 11:1127-35. doi:10.1038/ni.1953

30. Sun JC, Lanier LL. Natural killer cells remember: an evolutionary bridge between innate and adaptive immunity? Eur J Immunol (2009) 39(8):2059-64. doi:10.1002/eji.200939435

31. Min-Oo G, Kamimura Y, Hendricks DW, Nabekura T, Lanier LL. Natural killer cells: walking three paths down memory lane. Trends Immunol (2013) 34:251-8. doi:10.1016/j.it.2013.02.005

32. Guma M, Budt M, Saez A, Brckalo T, Hengel H, Angulo A, et al. Expansion of CD94/NKG2C+ NK cells in response to human cytomegalovirus-infected fibroblasts. Blood (2006) 107:3624-31. doi:10.1182/blood-2005-09-3682 
33. Guma M, Angulo A, Vilches C, Gomez-Lozano N, Malats N, Lopez-Botet M. Imprint of human cytomegalovirus infection on the NK cell receptor repertoire. Blood (2004) 104:3664-71. doi:10.1182/blood-2004-05-2058

34. Foley B, Cooley S, Verneris MR, Pitt M, Curtsinger J, Luo X, et al. Cytomegalovirus reactivation after allogeneic transplantation promotes a lasting increase in educated NKG2C+ natural killer cells with potent function. Blood (2012) 119:2665-74. doi:10.1182/blood-2011-10-386995

35. Rolle A, Pollmann J, Cerwenka A. Memory of infections: an emerging role for natural killer cells. PLoS Pathog (2013) 9:e1003548. doi:10.1371/journal.ppat. 1003548

36. Petitdemange C, Becquart P, Wauquier N, Béziat V, Debré P, Leroy EM, et al. Unconventional repertoire profile is imprinted during acute chikungunya infection for natural killer cells polarization toward cytotoxicity. PLoS Pathog (2011) 7:e1002268. doi:10.1371/journal.ppat.1002268

37. Bjorkstrom NK, Lindgren T, Stoltz M, Fauriat C, Braun M, Evander M, et al. Rapid expansion and long-term persistence of elevated NK cell numbers in humans infected with hantavirus. J Exp Med (2011) 208:13-21. doi:10.1084/jem.20100762

38. Labrecque N, Whitfield LS, Obst R, Waltzinger C, Benoist C, Mathis D. How much TCR does a T cell need? Immunity (2001) 15:71-82. doi:10.1016/S10747613(01)00170-4

39. Arase H, Mocarski E, Campbell A, Hill A, Lanier L. Direct recognition of cytomegalovirus by activating and inhibitory NK cell receptors. Science (2002) 296:1323-6. doi:10.1126/science.1070884

40. Muntasell A, Vilches C, Angulo A, ópez-Botet ML. Adaptive reconfiguration of the human NK-cell compartment in response to cytomegalovirus: a different perspective of the host-pathogen interaction. Eur J Immunol (2013) 43:1133-41. doi:10.1002/eji.201243117

41. Vivier E, Raulet DH, Moretta A, Caligiuri MA, Zitvogel L, Lanier LL, et al. Innate or adaptive immunity? The example of natural killer cells. Science (2011) 331:44-9. doi:10.1126/science.1198687

42. Horowitz A, Strauss-Albee DM, Leipold M, Kubo J, Nemat-Gorgani N, Dogan OC, et al. Genetic and environmental determinants of human NK cell diversity revealed by mass cytometry. Sci Transl Med (2013) 5:208ra145. doi:10.1126/scitranslmed.3006702

43. Brandt CS, Baratin M, Yi EC, Kennedy J, Gao Z, Fox B, et al. The B7 family member B7-H6 is a tumor cell ligand for the activating natural killer cell receptor NKp30 in humans. J Exp Med (2009) 206:1495-503. doi:10.1084/jem.20090681

44. Marras F, Bozzano F, De Maria A. Involvement of activating NK cell receptors and their modulation in pathogen immunity. J Biomed Biotechnol (2011) 2011:152430. doi:10.1155/2011/152430

45. Sivori S, Pende D, Bottino C, Marcenaro E, Pessino A, Biassoni R, et al. NKp46 is the major triggering receptor involved in the natural cytotoxicity of fresh or cultured human NK cells. Correlation between surface density of NKp46 and natural cytotoxicity against autologous, allogeneic or xenogeneic target cells. Eur J Immunol (1999) 29:1656-66. doi:10.1002/(SICI)1521-4141(199905)29: 05<1656::AID-IMMU1656>3.0.CO;2-1

46. Bisio F, Bozzano F, Marras F, Di Biagio A, Moretta L, De Maria A. Successfully treated HIV-infected patients have differential expression of NK cell receptors (NKp46 and NKp30) according to AIDS status at presentation. Immunol Lett (2013) 152:16-24. doi:10.1016/j.imlet.2013.03.003

47. Draghi M, Pashine A, Sanjanwala B, Gendzekhadze K, Cantoni C, Cosman D, et al. NKp46 and NKG2D recognition of infected dendritic cells is necessary for NK cell activation in the human response to influenza infection. J Immunol (2007) 178:2688-98. doi:10.4049/jimmunol.178.5.2688

48. Mandelboim O, Lieberman N, Lev M, Paul L, Arnon TI, Bushkin Y, et al. Recognition of haemagglutinins on virus-infected cells by NKp46 activates lysis by human NK cells. Nature (2001) 409:1055-60. doi:10.1038/35059110

49. Gazit R, Gruda R, Elboim M, Arnon TI, Katz G, Achdout H, et al. Lethal influenza infection in the absence of the natural killer cell receptor gene Ncrl. Nat Immunol (2006) 7:517-23. doi:10.1038/ni1322

50. Beli E, Clinthorne JF, Duriancik DM, Hwang I, Kim S, Gardner EM. Natural killer cell function is altered during the primary response of aged mice to influenza infection. Mech Ageing Dev (2011) 132:503-10. doi:10.1016/j.mad. 2011.08.005

51. Khakoo SI, Thio CL, Martin MP, Brooks CR, Gao X, Astemborski J, et al. HLA and NK cell inhibitory receptor genes in resolving hepatitis $\mathrm{C}$ virus infection. Science (2004) 305:872-4. doi:10.1126/science.1097670
52. Bashirova AA, Thomas R, Carrington M. HLA/KIR restraint of HIV: surviving the fittest. Annu Rev Immunol (2011) 29:295-317. doi:10.1146/annurevimmunol-031210-101332

53. Amadei B, Urbani S, Cazaly A, Fisicaro P, Zerbini A, Ahmed P, et al. Activation of natural killer cells during acute infection with hepatitis $\mathrm{C}$ virus. Gastroenterology (2010) 138:1536-45. doi:10.1053/j.gastro.2010.01.006

54. Golden-Mason L, Cox AL, Randall JA, Cheng L, Rosen HR. Increased natural killer cell cytotoxicity and $\mathrm{NKp} 30$ expression protects against hepatitis $\mathrm{C}$ virus infection in high-risk individuals and inhibits replication in vitro. Hepatology (2010) 52:1581-9. doi:10.1002/hep.23896

55. Werner JM, Heller T, Gordon AM, Sheets A, Sherker AH, Kessler E, et al. Innate immune responses in hepatitis $C$ virus-exposed healthcare workers who do not develop acute infection. Hepatology (2013) 58:1621-31. doi:10.1002/hep.26353

56. De Maria A, Cirillo C, Moretta L. Occurrence of human immunodeficiency virus type I (HIV-I)-specific cytolytic T cell activity in apparently uninfected children born to HIV-1-infected mothers. J Infect Dis (1994) 170:1296-9. doi:10.1093/infdis/170.5.1296

57. Rowland-Jones S, Nixon D, Aldhous M, Gotch F, Ariyoshi K, Hallam N, et al. HIV-specific cytotoxic T-cell activity in an HIV-exposed but uninfected infant. Lancet (1994) 341:860-1. doi:10.1016/0140-6736(93)93063-7

58. Alter G, Jost S, Rihn S, Reyor LL, Nolan BE, Ghebremichael M, et al. Reduced frequencies of NKp30+NKp46+, CD161+, and NKG2D+ NK cells in acute HCV infection may predict viral clearance. J Hepatol (2011) 55:278-88. doi:10.1016/j.jhep.2010.11.030

59. Krämer B, Körner C, Kebschull M, Glässner A, Eisenhardt M, Nischalke HD, et al. Natural killer p46High expression defines a natural killer cell subset that is potentially involved in control of hepatitis $\mathrm{C}$ virus replication and modulation of liver fibrosis. Hepatology (2012) 56:1201-13. doi:10.1002/hep.25804

60. Jinushi M, Takehara T, Tatsumi T, Kanto T, Miyagi T, Suzuki T, et al. Negative regulation of $\mathrm{NK}$ cell activities by inhibitory receptor CD94/NKG2A leads to altered NK cell-induced modulation of dendritic cell functions in chronic hepatitis C virus infection. J Immunol (2004) 173:6072-81. doi:10. 4049/jimmunol.173.10.6072

61. De Maria A, Fogli M, Mazza S, Basso M, Picciotto A, Costa P, et al. Increased natural cytotoxicity receptor expression and relevant IL-10 production in NK cells from chronically infected viremic HCV patients. Eur J Immunol (2007) 37:445-55. doi:10.1002/eji.200635989

62. Crotta S, Brazzoli M, Piccioli D, Valiante NM, Wack A. Hepatitis C virions subvert natural killer cell activation to generate a cytokine environment permissive for infection. J Hepatol (2010) 52:183-90. doi:10.1016/j.jhep.2009.11.003

63. Nattermann J, Feldmann G, Ahlenstiel G, Langhans B, Sauerbruch T, Spengler U. Surface expression and cytolytic function of natural killer cell receptors is altered in chronic hepatitis C. Gut (2006) 55:869-77. doi:10.1136/gut.2005. 076463

64. Bozzano F, Picciotto A, Costa P, Marras F, Fazio V, Hirsch I, et al. Activating NK cell receptor expression/function (NKp30, NKp46, DNAM-1) during chronic viraemic $\mathrm{HCV}$ infection is associated with the outcome of combined treatment Eur J Immunol (2011) 41:2905-14. doi:10.1002/eji.201041361

65. Honda M, Nakamura M, Tateno M, Sakai A, Shimakami T, Shirasaki T, et al. Differential interferon signaling in liver lobule and portal area cells under treatment for chronic hepatitis C. J Hepatol (2010) 53:817-26. doi:10.1016/j.jhep. 2010.04.036

66. Sarasin-Filipowicz M, Oakeley EJ, Duong FH, Christen V, Terracciano L, Filipowicz W, et al. Interferon signaling and treatment outcome in chronic hepatitis C. Proc Natl Acad Sci U S A (2008) 105:7034-9. doi:10.1073/pnas. 0707882105

67. Scott-Algara D, Truong LX, Versmisse P, David A, Luong TT, Nguyen NV, et al. Cutting edge: increased NK cell activity in HIV-1-exposed but uninfected vietnamese intravascular drug users. J Immunol (2003) 171:5663-7. doi:10.4049/jimmunol.171.11.5663

68. Poli G, Introna M, Zanaboni F, Peri G, Carbonari M, Aiuti F, et al. Natural killer cells in intravenous drug abusers with lymphadenopathy syndrome. Clin Exp Immunol (1985) 62:128-35.

69. Cai Q, Huang X, Rappocciolo G, Rinaldo CJ. Natural killer cell responses in homosexual men with early HIV infection. J Acquir Immune Defic Syndr (1990) 3:669-76

70. Scott-Algara D, Vuillier F, Cayota A, Dighiero G. Natural killer (NK) cell activity during HIV infection: a decrease in NK activity is observed at the clonal 
level and is not restored after in vitro long-term culture of NK cells. Clin Exp Immunol (1992) 90:181-7. doi:10.1111/j.1365-2249.1992.tb07925.x

71. Montaldo E, Zotto GD, Chiesa MD, Mingari MC, Moretta A, Maria AD, et al. Human NK cell receptors/markers: a tool to analyze NK cell development, subsets and function. Cytometry A (2013) 83A:702-13. doi:10.1002/cyto.a.22302

72. Fogli M, Costa P, Murdaca G, Setti M, Mingari MC, Moretta L, et al. Significant NK cell activation associated with decreased cytolytic function in peripheral blood of HIV-1-infected patients. Eur J Immunol (2004) 34:2313-21. doi:10.1002/eji.200425251

73. Matusali G, Tchidjou HK, Pontrelli G, Bernardi S, D'Ettorre G, Vullo V, et al. Soluble ligands for the NKG2D receptor are released during HIV-1 infection and impair NKG2D expression and cytotoxicity of NK cells. FASEB J (2013) 27:2440-50. doi:10.1096/fj.12-223057

74. Matusali G, Potestà M, Santoni A, Cerboni C, Doria M. The human immunodeficiency virus type $1 \mathrm{Nef}$ and $\mathrm{V}$ pu proteins downregulate the natural killer cellactivating ligand PVR. J Virol (2012) 86:4496-504. doi:10.1128/JVI.05788-11

75. Cerboni C, Neri F, Casartelli N, Zingoni A, Cosman D, Rossi P, et al. Human immunodeficiency virus 1 Nef protein downmodulates the ligands of the activating receptor NKG2D and inhibits natural killer cell-mediated cytotoxicity. J Gen Virol (2007) 88:242-50. doi:10.1099/vir.0.82125-0

76. Ward J, Bonaparte M, Sacks J, Guterman J, Fogli M, Mavilio D, et al. HIV modulates the expression of ligands important in triggering natural killer cell cytotoxic responses on infected primary T-cell blasts. Blood (2007) 110:1207-14. doi:10.1182/blood-2006-06-028175

77. Cao Y, Qin L, Zhang L, Safrit J, Ho DD. Virologic and immunologic characterization of long-term survivors of human immunodeficiency virus type 1 infection. N Engl J Med (1995) 332:201-8. doi:10.1056/NEJM199501263320401

78. Pantaleo G, Menzo S, Vaccarezza M, Graziosi C, Cohen OJ, Demarest JF, et al. Studies in subjects with long-term nonprogressive human immunodeficiency virus infection. $N$ Engl J Med (1995) 332:209-16. doi:10.1056/ NEJM199501263320402

79. Masur H, Ognibene F, Yarchoan R, Shelhamer J, Baird B, Travis W, et al. CD4 counts as predictors of opportunistic pneumonias in human immunodeficiency virus (HIV) infection. Ann Intern Med (1989) 111:223-31. doi:10.7326/ 0003-4819-111-3-223

80. De Maria A, Cossarizza A. CD4saurus Rex \&HIVelociraptor vs. development of clinically useful immunological markers: a Jurassic tale of frozen evolution. J Transl Med (2011) 9:93. doi:10.1186/1479-5876-9-93

81. Crowe S, Carlin J, Stewart K, Lucas C, Hoy J. Predictive value of CD4 lymphocyte numbers for the development of opportunistic infections and malignancies in HIV-infected persons. J Acquir Immune Defic Syndr (1991) 4:770-6.

82. Prosperi MC, Cozzi-Lepri A, Castagna A, Mussini C, Murri R, Giacometti A, et al. Incidence of malignancies in HIV-infected patients and prognostic role of current CD4 cell count: evidence from a large Italian cohort study. Clin Infect Dis (2010) 50:1316-21. doi:10.1086/651688

83. Girardi E, Antonucci G, Armignacco O, Salmaso S, Ippolito G. Tuberculosis and AIDS: a retrospective, longitudinal, multicentre study of Italian AIDS patients. Italian group for the study of tuberculosis and AIDS (GISTA). J Infect (1994) 28:261-9. doi:10.1016/S0163-4453(94)91693-4

84. Sirianni MC, Campagna M, Scaramuzzi D, Carbonari M, Toschi E, Bacigalupo I, et al. Control of human herpes virus type 8-associated diseases by NK cells. Ann N Y Acad Sci (2007) 1096:37-43. doi:10.1196/annals.1397.068

85. Maurer T, Ponte M, Leslie K. HIV-associated Kaposi's sarcoma with a high CD4 count and a low viral load. N Engl J Med (2007) 357:1352-3. doi:10.1056/ NEJMc070508

86. Ironson G, Balbin E, Solomon G, Fahey J, Klimas N, Schneiderman N, et al. Relative preservation of natural killer cell cytotoxicity and number in healthy AIDS patients with low CD4 cell counts. AIDS (2001) 15:2065-73. doi:10.1097/00002030-200111090-00001

87. Azzoni L, Rutstein RM, Chehimi J, Farabaugh MA, Nowmos A, Montaner LJ. Dendritic and natural killer cell subsets associated with stable or declining CD4+ cell counts in treated HIV-1-infected children. J Infect Dis (2005) 191:1451-9. doi:10.1086/429300

88. Azzoni L, Papasavvas E, Chehimi J, Kostman JR, Mounzer K, Ondercin J, et al. Sustained impairment of IFN-gamma secretion in suppressed HIV-infected patients despite mature NK cell recovery: evidence for a defective reconstitution of innate immunity. J Immunol (2002) 168:5764-70. doi:10.4049/jimmunol. 168.11 .5764
89. Lichtfuss GF, Cheng W-J, Farsakoglu Y, Paukovics G, Rajasuriar R, Velayudham P, et al. Virologically suppressed HIV patients show activation of NK cells and persistent innate immune activation. J Immunol (2012) 189:1491-9. doi:10.4049/jimmunol.1200458

90. Davey RT, Bhat N, Yoder C, Chun T-W, Metcalf JA, Dewar R, et al. HIV-1 and $\mathrm{T}$ cell dynamics after interruption of highly active antiretroviral therapy (HAART) in patients with a history of sustained viral suppression. Proc Natl Acad Sci U S A (1999) 96:15109-14. doi:10.1073/pnas.96.26.15109

91. Maggiolo F, Airoldi M, Callegaro A, Martinelli C, Dolara A, Bini T, et al. CD4 cell-guided scheduled treatment interruptions in HIV-infected patients with sustained immunologic response to HAART. AIDS (2009) 23(7):799-807. doi:10.1097/QAD.0b013e328321b75e

92. Mussini C, Bedini A, Borghi V, Guaraldi G, Esposito R, Barchi E, et al. CD4 cell-monitored treatment interruption in patients with a CD4 cell count $>500$ $\times 106$ cells/l. AIDS (2005) 19:287-94.

93. Sarmati L, Andreoni C, Nicastri E, Tommasi C, Buonomini A, D’Ettorre G, et al. Prognostic factors of long-term CD4+count-guided interruption of antiretroviral treatment. J Med Virol (2009) 81:481-7. doi:10.1002/jmv.21424

94. Nemes E, Lugli E, Nasi M, Ferraresi R, Pinti M, Bugarini R, et al. Immunophenotype of HIV+ patients during CD4 cell-monitored treatment interruption: role of the IL-7/IL-7 receptor system. AIDS (2006) 20:2021-32. doi:10.1097/ 01.aids.0000247575.41622.b1

95. Nasi M, Pinti M, Manzini S, Gibellini L, Manzini L, Bisi L, et al. Cossarizza, predictive value of intracellular HIV-1 DNA levels during CD4-guided treatment interruption in HIV+ patients. AIDS Res Hum Retroviruses (2010) 26:553-8. doi:10.1089/aid.2009.0256

96. Bozzano F, Nasi M, Bertoncelli L, Nemes E, Prati F, Marras F, et al. NKcell phenotype at interruption underlies widely divergent duration of CD4+guided antiretroviral treatment interruption. Int Immunol (2011) 23:109-18. doi:10.1093/intimm/dxq462

97. Delahaye NF, Rusakiewicz S, Martins I, Menard C, Roux S, Lyonnet L, et al. Alternatively spliced NKp30 isoforms affect the prognosis of gastrointestinal stromal tumors. Nat Med (2011) 17:700-7. doi:10.1038/nm.2366

98. Ascierto M, Idowu M, Zhao Y, Khalak H, Payne K, Wang X-Y, et al. Molecular signatures mostly associated with NK cells are predictive of relapse free survival in breast cancer patients. J Transl Med (2013) 11:145. doi:10.1186/1479-587611-145

99. Marras F, Nicco E, Bozzano F, Di Biagio A, Dentone C, Pontali E, et al. Natural killer cells in HIV controller patients express an activated effector phenotype and do not up-regulate NKp44 on IL-2 stimulation. Proc Natl Acad Sci U S A (2013) 110(29):11970-5. doi:10.1073/pnas.1302090110

100. Tomescu C, Duh F-M, Hoh R, Viviani A, Harvill K, Martin MP, et al. Impact of protective killer inhibitory receptor/human leukocyte antigen genotypes on natural killer cell and T-cell function in HIV-1-infected controllers. AIDS (2012) 26:1869-78. doi:10.1097/QAD.0b013e32835861b0

101. Mothe B, Llano A, Ibarrondo J, Zamarreño J, Schiaulini M, Miranda C, et al. CTL responses of high functional avidity and broad variant cross-reactivity are associated with HIV control. PLoS One (2012) 7:e29717. doi:10.1371/journal. pone. 0029717

102. Vieillard V, Strominger JL, Debré P. NK cytotoxicity against CD4+ T cells during HIV-1 infection: a gp41 peptide induces the expression of an NKp44 ligand. Proc Natl Acad Sci U S A (2005) 102:10981-6. doi:10.1073/pnas. 0504315102

103. Vieillard V, Dereuddre-Bosquet N, Mangeot-Méderlé I, Le Grand R, Debré P. An HIVgp41 vaccine protects CD4 central memory T cells in SHIV-infected macaques. Vaccine (2012) 30:6883-91. doi:10.1016/j.vaccine.2012.09.004

104. Lai CB, Mager DL. Role of runt-related transcription factor 3 (RUNX3) in transcription regulation of natural cytotoxicity receptor 1 (NCR1/NKp46), an activating natural killer (NK) cell receptor. J Biol Chem (2012) 287:7324-34. doi:10.1074/jbc.M111.306936

105. Herrmann J, Berberich H, Hartmann J, Beyer S, Davies K, Koch J. Homooligomerization of the activating natural killer cell receptor NKp30 ectodomain increases its binding affinity for cellular ligands. J Biol Chem (2013) 289:765-77. doi:10.1074/jbc.M113.514786

106. Jarahian M, Fiedler M, Cohnen A, Djandji D, Hämmerling GJ, Gati C, et al. Modulation of NKp30- and NKp46-mediated natural killer cell responses by poxviral hemagglutinin. PLoS Pathog (2011) 7:e1002195. doi:10.1371/journal. ppat. 1002195 
107. Tripathy SK, Keyel PA, Yang L, Pingel JT, Cheng TP, Schneeberger A, et al. Continuous engagement of a self-specific activation receptor induces NK cell tolerance. J Exp Med (2008) 205:1829-41. doi:10.1084/jem.20072446

108. Pamer EG. TLR polymorphisms and the risk of invasive fungal infections. $N$ Engl J Med (2008) 359:1836-8. doi:10.1056/NEJMe0806412

109. Bochud P-Y, Chien JW, Marr KA, Leisenring WM, Upton A, Janer M, et al. Tolllike receptor 4 polymorphisms and aspergillosis in stem-cell transplantation. N Engl J Med (2008) 359:1766-77. doi:10.1056/NEJMoa0802629

110. Kesh S, Mensah NY, Peterlongo P, Jaffe D, Hsu K, Van Den Brink M, et al. TLR1 and TLR6 polymorphisms are associated with susceptibility to invasive aspergillosis after allogeneic stem cell transplantation. Ann N Y Acad Sci (2005) 1062:95-103. doi:10.1196/annals.1358.012

111. Cunha C, Aversa F, Lacerda JF, Busca A, Kurzai O, Grube M, et al. Genetic PTX3 deficiency and aspergillosis in stem-cell transplantation. N Engl J Med (2014) 370:421-32. doi:10.1056/NEJMoa1211161

112. Esposito S, Molteni C, Giliani S, Mazza C, Scala A, Tagliaferri L, et al. Tolllike receptor 3 gene polymorphisms and severity of pandemic A/H1N1/2009 influenza in otherwise healthy children. Virol J (2012) 9:270. doi:10.1186/1743422X-9-270

113. Thomas DL, Thio CL, Martin MP, Qi Y, Ge D, O'Huigin C, et al. Genetic variation in IL28B and spontaneous clearance of hepatitis C virus. Nature (2009) 461:798-801. doi:10.1038/nature08463

114. Tanaka Y, Nishida N, Sugiyama M, Kurosaki M, Matsuura K, Sakamoto N, et al. Genome-wide association of IL28B with response to pegylated interferon[alpha] and ribavirin therapy for chronic hepatitis C. Nat Genet (2009) 41:1105-9. doi:10.1038/ng.449

115. Mangia A, Thompson AJ, Santoro R, Piazzolla V, Tillmann HL, Patel K, et al. An IL28B polymorphism determines treatment response of hepatitis $\mathrm{C}$ virus genotype 2 or 3 patients who do not achieve a rapid virologic response. Gastroenterology (2010) 139:821.e-7.e. doi:10.1053/j.gastro.2010.05.079
116. Clausen LN, Weis N, Astvad K, Schønning K, Fenger M, Krarup H, et al. Interleukin-28B polymorphisms are associated with hepatitis $\mathrm{C}$ virus clearance and viral load in a HIV-1-infected cohort. J Viral Hepat (2011) 18:e66-74. doi:10.1111/j.1365-2893.2010.01392.x

117. Rutjens E, Mazza S, Biassoni R, Koopman G, Radic L, Fogli M, et al. Differential NKp30 inducibility in chimpanzee NK cells and conserved NK cell phenotype and function in long-term HIV-1-infected animals. J Immunol (2007) 178:1702-12. doi:10.4049/jimmunol.178.3.1702

Conflict of Interest Statement: The Guest Associate Editor Massimo Vitale declares that, despite being affiliated to the same institution as author Andrea De Maria, the review process was handled objectively and no conflict of interest exists. The authors declare that the research was conducted in the absence of any commercial or financial relationships that could be construed as a potential conflict of interest.

Received: 24 February 2014; accepted: 16 June 2014; published online: 02 July 2014. Citation: Marras F, Bozzano F, Ascierto ML and De Maria A (2014) Baseline and dynamic expression of activating $N K$ cell receptors in the control of chronic viral infections: the paradigm of HIV-1 and HCV. Front. Immunol. 5:305. doi: 10.3389/fimmu.2014.00305

This article was submitted to NK Cell Biology, a section of the journal Frontiers in Immunology.

Copyright (c) 2014 Marras, Bozzano, Ascierto and De Maria. This is an open-access article distributed under the terms of the Creative Commons Attribution License (CC $B Y)$. The use, distribution or reproduction in other forums is permitted, provided the original author(s) or licensor are credited and that the original publication in this journal is cited, in accordance with accepted academic practice. No use, distribution or reproduction is permitted which does not comply with these terms. 